\title{
POLIITICAS DE GESTÃO DE PESSOAS, COMPROMETIMENTO ORGANIZACIONAL E SATISFACÃO NO TRABALHO NA LIVRARIA CULTURA
} PEOPLE MANAGEMENT POLICIES, ORGANIZATIONAL COMMITMENT AND JOB SATISFACTION AT THE LIVRARIA CULTURA BOOKSHOP

POLÍTICAS DE GESTIÓN DE PERSONAS, COMPROMISO ORGANIZACIONAL Y SATISFACCIÓN EN EL TRABAJO EN LA LIBRERÍA CULTURA

Gisela Demo

Doutora

Universidade de Brasília (UnB) giselademo@gmail.com

Paula de Rezende Martins

Especialista

Fundação Getúlio Vargas (FGV-DF) paularezins@gmail.com

Patricia Roure Mestranda Universidade de Brasília (UnB) patriciasroure@gmail.com

Submetido em: 20/08/2012

Aprovado em: 09/04/2013

\section{RESUMO}

Os principais autores da área de Gestão de Pessoas (GP), como Legge (2006) e Wilkinson, Bacon, Redman e Snell (2010), concordam que as pessoas assumiram papel estratégico e relevante nas organizações. Considerando que as políticas de GP precisam contribuir para um maior comprometimento e satisfação no trabalho, esta pesquisa propôs-se a avaliar a relação existente entre tais variáveis, segundo a percepção dos colaboradores da Livraria Cultura, filial Brasília. Foram feitas análises de regressão linear múltipla padrão e hierárquica para testar e confirmar as relações dos modelos propostos. Os resultados confirmaram que as políticas de GP são preditoras do comprometimento organizacional e, mais ainda, da satisfação no trabalho. Esta pesquisa contribui para o avanço de estudos da área de Gestão de Pessoas e Psicologia Organizacional, apresentando uma maneira inovadora de mensurar políticas de GP e, para a organização pesquisada, serve como um diagnóstico, subsidiando os gestores da empresa em suas tomadas de decisão no afã de melhorar a satisfação e o comprometimento de seus colaboradores, o que pode traduzir-se em resultados organizacionais superiores. Limitações e recomendações para estudos futuros são discutidas.

PALAVRAS-CHAVE: Políticas de Gestão de Pessoas. Comprometimento organizacional. Satisfação no Trabalho.

\section{ABSTRACT}

The main authors in the area of Human Resources Management (HRM), including Legge (2006) and Wilkinson, Bacon, Redman and Snell (2010), agree that people have assumed an important and strategic 
role in organizations. Given that HRM policies need to contribute to greater commitment and job satisfaction, this study evaluates the relationship between these variables as perceived by the employees of the Brasília branch of the bookshop Livraria Cultura. Standard and hierarchical multiple linear regressions were performed to test and confirm the relationship of the proposed models. The results confirmed that HRM policies are predictors of organizational commitment, and even more so of job satisfaction. This research contributes to the advancement of studies in the area of Human Resource Management and Organizational Psychology by presenting an innovative way to measure HRM policies. Furthermore, for Livraria Cultura, the findings serve as a diagnosis, assisting managers in their decision-making process in order to improve the job satisfaction and commitment of its employees and thereby improve organizational outcomes. Some limitations of the study, and directions for further research are discussed.

KEYWORDS: Human Resource Management Policies. Organizational Commitment. Job Satisfaction.

\section{RESUMEN}

Los principales autores del área de Gestión de Personas (GP), como Legge (2006) y Wilkinson, Bacon, Redman y Snell (2010), coinciden en que las personas asumieron un rol estratégico y relevante en las organizaciones. Considerando que las políticas de GP necesitan contribuir a un mayor compromiso y satisfacción en el trabajo, esta investigación se propuso evaluar la relación existente entre tales variables según la percepción de los colaboradores de la Librería Cultura, sucursal Brasília. Se realizaron análisis de regresión lineal múltiple patrón y jerárquica para testear y confirmar las relaciones de los modelos propuestos. Los resultados confirmaron que las políticas de GP son predictoras del compromiso organizacional y, además, de la satisfacción en el trabajo. Esta investigación contribuye para el avance de estudios en el área de Gestión de Personas y Psicología Organizacional, presentando una manera innovadora de mensurar políticas de GP, y para la organización investigada sirve como un diagnóstico, dando bases a los gestores de la empresa en sus tomas de decisión en su afán de mejorar la satisfacción y el compromiso de sus colaboradores, lo que puede traducirse en resultados organizacionales superiores. Se debaten las limitaciones y recomendaciones para estudios futuros.

PALABRAS ClaVe: Políticas de Gestión de Personas. Compromiso Organizacional. Satisfacción en el Trabajo.

\section{INTRODUÇÃO}

Os principais autores da área de Gestão de Pessoas (GP), como Guest (1987), Legge (2006), Boxall, Purcell e Wright (2007), Armstrong (2009) e Wilkinson, Bacon, Redman e Snell (2010), concordam que as pessoas assumiram papel estratégico e relevante nas organizações, já que suas políticas e práticas devem criar capacidades organizacionais que levam a uma competitividade maior. No momento em que fontes tradicionais de vantagem competitiva, como tecnologia, não são mais consideradas suficientes para garantir uma posição competitiva sustentável, as pessoas passam a ser competências essenciais de diferenciação estratégica.

No Brasil, no final da década de 80 , era patente a situação incipiente da GP estratégica. Na prática, a participação da área se restringia à administração de processos operacionais. Não obstante, na década de 90, o país sofre profundas modificações no cenário econômico, afetando diretamente o padrão de competitividade das organizações e a própria mudança de nomenclatura, de $\mathrm{RH}$ para GP, o que traduz a necessidade de as empresas se inserirem no mercado global. A partir daí, as políticas de GP voltam-se ao envolvimento e à participação das pessoas nas organizações, delineando as novas perspectivas da atual GP no Brasil, em consonância com o cenário internacional (DEMO; NUNES; FOGAÇA; BARCELOS; ROURE, 2012). 
Conforme apontado por Siqueira (2008), novos estudos sinalizam a interdependência entre satisfação e comprometimento no trabalho e políticas e práticas gerenciais, como, por exemplo, políticas e práticas de GP. Ademais, o estudo conduzido por Katou (2012) mostrou que as políticas de GP têm um efeito positivo sobre o desempenho organizacional avaliado por meio de atitudes (satisfação, comprometimento, motivação) e comportamentos (faltas, volume de negócios, disputas) dos empregados. Destarte, esta pesquisa propôs-se a responder ao seguinte questionamento: políticas de gestão de pessoas são preditoras de comprometimento organizacional e satisfação no trabalho a partir da percepção dos colaboradores da filial de Brasília da Livraria Cultura?

Posto isso, o principal objetivo desta pesquisa foi investigar a relação entre a variável percepção de políticas de gestão de pessoas - variável independente - e as variáveis comprometimento organizacional e satisfação no trabalho - variáveis dependentes -, identificando os melhores preditores do comprometimento organizacional e da satisfação no trabalho e, ainda, confirmando os resultados de pesquisas científicas anteriores sobre o tema (BORGES; MARQUES; ADORNO, 2006; KATOU, 2012). Buscou-se também identificar a percepção dos colaboradores quanto às políticas de GP, seu comprometimento com a empresa e satisfação no trabalho. A Livraria Cultura foi escolhida por ser um ícone brasileiro, referência no mercado varejista com 60 anos e 17 lojas presentes em 8 estados do Brasil no ano de 2012. Conta com o maior acervo de títulos do mercado brasileiro: mais de 5,8 milhões de títulos em livros, além de 560 mil CDs, DVDs, games, revistas e uma linha de produtos exclusivos.

Para consecução dos objetivos propostos, será enunciado, em primeira instância, o referencial teórico do trabalho, visitando os estudos sobre políticas de GP, comprometimento organizacional e satisfação no trabalho. Em seguida, será apresentado o método, englobando os modelos da pesquisa, a caracterização da pesquisa, organização, amostra e os instrumentos utilizados e, por fim, os procedimentos de coleta e análise dos dados. Seguem os resultados coligidos e sua discussão que, por sua vez, fomentarão as conclusões da pesquisa, mormente no que tange às suas contribuições e recomendações para estudos futuros.

\section{REFERENCIAL TEÓRICO}

\section{Políticas de Gestão de Pessoas}

A GP, em sua versão mais atual, entende o colaborador como fundamental no processo de consecução de metas e tomada de decisões em busca de maior efetividade e competitividade organizacionais, tornando-se um fator estratégico. Portanto, as políticas de GP precisam ser modificadas para se ajustarem à estratégia empresarial e efetivamente valorizar os colaboradores (DEMO et al., 2012). Ulrich, Halbrook, Meder, Stuchlik e Thorpe (1991) afirmam que o panorama competitivo se altera constantemente, demandando novos modelos de competitividade que, por seu turno, exigem capacidades organizacionais que possibilitarão às empresas atenderem melhor os seus clientes e se diferenciarem de seus concorrentes. Estas capacidades organizacionais derivam da redefinição e da redistribuição das práticas, das funções e dos profissionais de GP. Resumindo, na visão de autores como Guest (1987), Storey (1995) e Legge (2006), é possível observar que as pessoas assumiram papel estratégico e relevante nas organizações, que sua gestão deve ser devidamente suportada por teorias coesas e consistentes e, ainda, que precisa estar alinhada ao planejamento e à estratégia organizacional.

A importância das políticas de GP para as organizações tem crescido nos últimos anos, o que pode ser constatado pelo aumento da produção acadêmica sobre o tema. Em âmbito internacional, alguns autores discutiram as vantagens competitivas advindas da GP. Beauvallet e Houy (2010) sustentam que os mecanismos chaves e as variáveis decisivas que justificariam as vantagens competitivas das empresas ditas enxutas, ou que praticam gerenciamento sem gorduras, estão diretamente relacionados à GP. Conforme Pfeffer (2010), a área de GP é fundamental no desenvolvimento de conceitos e práticas de sustentabilidade, o que se traduz em ganhos de competitividade.

Há um consenso de que políticas de GP produzem desempenho organizacional superior quando são utilizadas em conjunto e de maneira integrada à estratégia de negócios (BOSELIE; DIETZ; 
BOON, 2005; EZZAMEL; LILLEY; WILKINSON; WILLMOTT, 1996; GUEST; HOQUE, 1994; MENEZES; WOOD; GELADE, 2010; SUBRAMONY, 2009). Na mesma linha, Guest e Conway (2011) confirmaram a associação entre a adoção de mais práticas de GP, maior efetividade organizacional e melhorias em uma série de indicadores de desempenho. O estudo conduzido por Katou (2012), por seu turno, mostrou que as políticas de GP têm um efeito positivo sobre o desempenho organizacional avaliado por meio de atitudes (satisfação, comprometimento, motivação) e comportamentos (faltas, volume de negócios, disputas) dos empregados.

As políticas de GP definem o posicionamento, as expectativas e os valores da organização quando se referem à forma de tratamento dos indivíduos, e servem, ainda, como ponto de referência para o desenvolvimento de práticas organizacionais e para as decisões tomadas pelas pessoas, além de promover um tratamento equitativo entre os indivíduos (ARMSTRONG, 2009). Neste trabalho, optou-se por utilizar o termo política de GP na acepção de proposta articulada da organização, com construções teóricas e práticas, no trato das relações humanas, com vista à obtenção de resultados desejados. Dessa forma, as políticas de GP definem o referencial teórico e prático construído para possibilitar a consecução dos objetivos e das finalidades da organização, funcionando como guias de pensamento e ação para a área de GP.

Demo, Fogaça, Nunes, Edrei e Francischeto (2011) realizaram uma revisão da produção nacional sobre políticas de GP em periódicos no período compreendido entre 2000 e 2010 . Foram considerados os periódicos científicos de nível superior (maior ou igual à Qualis B2) da área de Administração, resultando em 108 artigos. Os resultados engendrados apontaram a relevância estratégica para as organizações dos estudos sobre políticas de gestão de pessoas, não obstante se destacou a premência de se realizar mais estudos sobre o tema, uma vez que algumas políticas, embora estratégicas, ainda são bem pouco investigadas. Há lacunas na literatura também no que tange ao desenvolvimento e à validação de instrumentos e à realização de ensaios teóricos. Em síntese, sugere-se relacionar as políticas e as práticas de GP a outras variáveis do Comportamento Organizacional e combinar diferentes perspectivas metodológicas para analisar com maior propriedade seus efeitos no bemestar dos colaboradores e nos resultados organizacionais.

Este trabalho adotou o modelo proposto por Demo et al. (2011). As políticas de GP selecionadas estão elencadas no Quadro 1.

Quadro 1. Políticas de GP

\begin{tabular}{|c|c|}
\hline Políticas de GP & Descrição \\
\hline Envolvimento & $\begin{array}{l}\text { Proposta articulada da organização, com construções teóricas e práti- } \\
\text { cas, para criar um vínculo afetivo com seus colaboradores, contribuindo } \\
\text { para seu bem-estar, em termos de reconhecimento, relacionamento, } \\
\text { participação e comunicação. }\end{array}$ \\
\hline $\begin{array}{l}\text { Treinamento, Desenvolvimento } \\
\text { \& Educação }\end{array}$ & $\begin{array}{l}\text { Proposta articulada da organização, com construções teóricas e } \\
\text { práticas, para prover aos colaboradores a aquisição sistemática de } \\
\text { competências e estimular a contínua aprendizagem e a produção de } \\
\text { conhecimento. }\end{array}$ \\
\hline Condições de Trabalho & $\begin{array}{l}\text { Proposta articulada da organização, com construções teóricas e práti- } \\
\text { cas, para prover aos colaboradores boas condições de trabalho em } \\
\text { termos de benefícios, saúde, segurança e tecnologia. }\end{array}$ \\
\hline Recompensas & $\begin{array}{l}\text { Proposta articulada da organização, com construções teóricas e } \\
\text { práticas, para recompensar o desempenho e as competências dos } \\
\text { colaboradores em termos de remuneração e incentivos. }\end{array}$ \\
\hline
\end{tabular}




\section{Comprometimento Organizacional}

O vínculo do colaborador e da empresa já vem sendo estudado desde o século $X X$, despertando um interesse maior com o início do processo de globalização. Tenbrunsel, Galvin, Neale e Bazerman (2004) ressaltam que o comprometimento no trabalho é oriundo da categoria de contratos psicológicos entre organização e empregados, dentro da disciplina do Comportamento Organizacional. Esses autores trabalham o construto como um conceito atitudinal, em função de ser uma variável interveniente ou um elo não observável entre estímulos observáveis e uma resposta observável, incluindo tendências cognitivas e comportamentais.

Medeiros, Albuquerque, Siqueira e Marques (2003) acrescentam que o século XX mostrou diversas pesquisas, abordando o comprometimento como um construto multidimensional, de modo a entender os indivíduos e os seus complexos vínculos com a organização. Não obstante, Demo (2003, p. 190) ressalta que os estudos sobre comprometimento "têm se concentrado no foco organizacional e na base afetiva, tanto no Brasil quanto no exterior". A autora sustenta ainda que o vínculo do comprometimento organizacional pode ser baseado em múltiplos processos psicológicos, além de poder ser estudado sob múltiplos focos, tais como com a organização, com a carreira e com o sindicato.

Quanto às bases do comprometimento, Bastos (1998) as enumera, a saber, afetiva/atitudinal (processo de identificação do indivíduo com os objetivos e os valores da organização); instrumental/ calculativa/de continuação (produto das recompensas e custos percebidos pelo empregado na condição de integrante da organização); sociológica (vínculo que surge das relações de autoridade com o empregador); normativa (conjunto de pressões de normas sociais que definem o vínculo do empregado com a empresa) e comportamental (tal conceito existe em relação a um conjunto de cognições que guiam os comportamentos que fortalecem o vínculo com a organização, como, por exemplo, chegar pontualmente ao trabalho). Essas diferentes bases têm conduzido a tipologias de comprometimento, como mostram os trabalhos de Meyer, Allen e Smith (1993), que apresentam um modelo tridimensional de comprometimento: afetivo, de continuação (ou calculativo ou instrumental) e normativo.

Allen e Meyer (1990) caracterizaram as bases do comprometimento organizacional. Dessa forma, os autores apontam que empregados com forte comprometimento afetivo permanecem na organização porque desejam fazê-lo; aqueles com comprometimento calculativo permanecem porque precisam; e aqueles com comprometimento normativo permanecem porque sentem que são obrigados. Para Mowday, Porter e Steers (1982), o comprometimento afetivo pode ser definido pelas suas principais características, a saber: crença e aceitação dos objetivos e valores organizacionais; disposição para defender a organização; e desejo de manter o vínculo com ela. Para os autores, este tipo de comprometimento vai além da simples lealdade passiva à organização, perfazendo uma relação ativa na qual o colaborador deseja dar algo de si, a fim de contribuir para o bem-estar da organização em que trabalha.

Segundo Siqueira e Gomide Júnior (2004), enquanto o comprometimento afetivo contempla as ligações afetivas com a organização e insere-se no âmbito da afetividade, tanto o comprometimento calculativo quanto o normativo representam dimensões cognitivas particulares da relação entre colaborador e organização. Siqueira (2000) sugere que o comprometimento calculativo pode ser vislumbrado pelo ato de o colaborador permanecer na organização a partir da motivação de percepções individuais sobre custos/perdas de investimento decorrentes do desligamento da organização. Ou seja, a organização contará com o colaborador enquanto ela for atraente para ele. A mesma autora afirma que as crenças do colaborador sobre a dívida social para com a organização, ou a necessidade de retribuir um favor integram o comprometimento organizacional normativo.

Dessa forma, os colaboradores que possuem alto nível de comprometimento normativo se sentem presos à organização que, por sua vez, possui diferentes formas de fazer com que seus colaboradores se sintam incapazes de abandoná-la. Nessas organizações, existe grande contato entre organização e colaboradores de forma semelhante a uma família com regras de conduta e missão muito fortes, de modo a levar o colaborador à convicção de que a organização necessita dele para continuar obtendo sucesso. Em outras palavras, os colaboradores que são comprometidos normativamente continuam trabalhando para a organização por um sentimento de dívida ou, ainda, obrigação. Portanto, se o colaborador permanece na organização porque se sente moralmente vinculado a ela ou aos colegas, verifica-se a presença do comprometimento normativo. 
A produção nacional recente sobre comprometimento no trabalho é vigorosa, com crescente interesse dos pesquisadores sobre o tema. O comprometimento organizacional tem sido investigado em diversos setores de atividades como educacional, portuário, hospitalar, agroindustrial, bancário e tecnológico. Contudo, o principal foco dos estudos é o organizacional e a principal base investigada é a afetiva. Observou-se, também, uma presença massiva de estudos quantitativos como os que relacionaram o comprometimento à espiritualidade nas organizações (REGO; CUNHA; SOUTO, 2007), aos vínculos empregatícios e à qualidade de vida no trabalho (SCHIRRMEISTER; NUNES; LIMONGIFRANÇA; GONÇALVES, 2008), à justiça organizacional (RIBEIRO, 2008) e à geração de vantagem competitiva sustentável (CHANG JUNIOR; SANTOS; SILVA; CHANG; NOGUEIRA, 2007).

Em suma, apesar da aparente consolidação dos estudos sobre o tema, sugere-se a realização de trabalhos de desenvolvimento teórico, pesquisas no terceiro setor, investigações que integrem as múltiplas bases e os focos do comprometimento, e uma combinação de diferentes perspectivas metodológicas para se compreender melhor o construto.

No presente estudo, utilizou-se o foco organizacional do comprometimento, contemplando as três bases mais estudadas, a saber, afetiva, calculativa e normativa, segundo as definições de Siqueira (2008), mostradas no Quadro 2.

Quadro 2. Bases do Comprometimento Organizacional

\begin{tabular}{|ll|}
\hline Bases do Comprometimento & Descrição \\
\hline Afetivo & $\begin{array}{l}\text { Processo de identificação do indivíduo com os objetivos e os va- } \\
\text { lores da organização. Equivalente científico de "vestir a camisa da } \\
\text { organização". }\end{array}$ \\
\hline Calculativo & $\begin{array}{l}\text { Produto de recompensas e custos percebidos pelo colaborador na } \\
\text { condição de integrante da organização. }\end{array}$ \\
\hline Normativo & $\begin{array}{l}\text { Conjunto de pressões de normas sociais que definem o vínculo do } \\
\text { colaborador com a empresa. }\end{array}$ \\
\hline Fonte: Adaptado de SIQUEIRA, M. M. M. Comprometimento organizacional. In: SIQUEIRA, M. M. M. (Org.).
\end{tabular}

Medidas do comportamento organizacional: ferramentas de diagnóstico e de gestão. Porto Alegre: Artmed, 2008. p. 49-95.

\section{Satisfação no Trabalho}

A satisfação no trabalho é uma variável importante para os estudos organizacionais. Staw e Ross (1985) ressaltam que esta é uma das variáveis mais comumente estudadas em Psicologia Organizacional. Martinez (2002) explica que, no século XX, o construto satisfação era relacionado ao processo motivacional, tendo, portanto, certa ligação com as teorias relacionadas ao comportamento no trabalho, como a teoria da hierarquia das necessidades de Maslow, de 1970; a teoria X e Y, elaborada por McGregor em 1960; e a teoria dos dois fatores de Herzberg, Mausner e Snyderman, de 1959.

Sob esse prisma, Siqueira (1995) advoga que os administradores começaram a defender a satisfação como causa de comportamentos dos seus colaboradores no trabalho, refletindo, assim, em desempenho, produtividade, rotatividade e absenteísmo. Segundo a autora, da década de 1980 em diante a satisfação passou a ser entendida como uma atitude, detentora de componentes afetivos e cognitivos, capaz de predizer diversos comportamentos no trabalho.

Apesar do empenho dos pesquisadores, não há consenso a respeito da definição e da natureza do construto satisfação no trabalho. Na visão de Marinho (1988), há uma tendência em caracterizar o construto de acordo com uma natureza afetiva, ainda que o próprio autor vislumbre um traço disposicional. Weiss (2002) conceituou o construto como um julgamento positivo ou negativo que um indivíduo possui sobre o seu trabalho ou determinada situação de trabalho. Por sua vez, Hazan e Shaver (1990) ressaltam a relação entre o trabalho e os vínculos afetivos do colaborador. Outros estudos investigaram a relação entre satisfação e variáveis relacionadas ao trabalho e ao colaborador. A relação entre satisfação no trabalho e na rotatividade foi investigada por Hellman 
(1997), enquanto Krausz, Koslowsky e Eiser (1998) pesquisaram a relação do construto com o absenteísmo, e Butler e Ehrich (1991) relacionaram a satisfação no trabalho com o desempenho do colaborador na organização. Dessa forma, entende-se que a satisfação no trabalho já foi estudada tanto como uma variável preditora quanto como critério em muitos estudos.

No século XXI, o construto satisfação é vislumbrado como um dos vários conceitos que se relacionam à afetividade no trabalho. Siqueira (2008) determina o enfoque do construto como sendo o resultado do ambiente organizacional sobre a saúde do colaborador. Para a autora, a satisfação pode ser apontada como um dos três componentes psicossociais do conceito de bemestar no trabalho, juntamente com o envolvimento, com o trabalho e com o comprometimento organizacional afetivo.

Siqueira e Gomide Júnior (2004) expõem que, quanto à dimensionalidade, a satisfação pode ser considerada como um conjunto de reações específicas a vários componentes do trabalho, capazes de desencadear no indivíduo diferentes graus de satisfação/insatisfação (visão multidimensional). De acordo com essa visão, diferentes aspectos do trabalho são considerados como fontes de satisfação no trabalho, sendo os mais frequentes os fatores chefia, colegas de trabalho, o próprio trabalho, salário e oportunidades de promoção. Enquanto chefia e colegas de trabalho constituem-se em dimensões relativas ao ambiente social, o próprio trabalho representa as atividades realizadas. Salário e oportunidades de promoção são, por sua vez, aspectos da gestão de pessoas por meio dos quais a organização manifesta sua retribuição ao empregado, constituindo-se em duas maneiras possíveis do empregado observar resultados de seus investimentos na organização e avaliar sua relação de troca com esta.

Consoante com essa proposta, a presente pesquisa utilizou a concepção de satisfação no trabalho como um atributo afetivo relativo ao grau de contentamento do colaborador frente ao seu trabalho, sendo, portanto, uma variável atitudinal com enfoque pós-cognitivo e caráter multidimensional. Dentro desse escopo, a satisfação é "[...] um elo afetivo com o trabalho, que se desenvolve a partir de cognições elaboradas pelo empregado sobre sua relação de troca social com o sistema [...]" (SIQUEIRA, 1995, p. 160). Ou, ainda,

[...] como um resultado (output) do ambiente organizacional sobre a saúde do trabalhador e é apontada como um dos três componentes psicossociais do conceito de bem-estar no trabalho, ao lado de envolvimento com o trabalho e comprometimento organizacional afetivo (SIQUEIRA, 2008, p. 266).

Em âmbito nacional, nos últimos cinco anos, o construto satisfação no trabalho foi relacionado a diferentes variáveis, quais sejam: comprometimento organizacional, estresse ocupacional, clima organizacional, desempenho, modernidade organizacional, absenteísmo e rotatividade (BERNSTORFF, 2007a, 2007b; BERNSTORFF; DAL ROSSO, 2008; CAMPOS; MALIK, 2008; CÚNICO; ZAMPIER, 2008). No que diz respeito à satisfação no trabalho a partir de uma perspectiva multinível, Puente-Palacios e Borges-Andrade (2005) realizaram um estudo no qual se levantou a hipótese da participação de variáveis preditoras relativas tanto aos indivíduos quanto às equipes, concluindo que a satisfação não é explicada somente sob uma perspectiva, individual ou coletiva, e sim pela exploração do efeito conjunto de variáveis. Contributivas também foram as tentativas de validação e revalidação de escalas para mensuração da satisfação (COELHO JUNIOR; MOURA, 2008; SANT'ANNA; MORAES; KILIMNIK, 2005), não obstante, a mais utilizada no Brasil ainda é a versão reduzida da escala de Siqueira (2008).

Em linhas gerais, a produção nacional recente a respeito da satisfação no trabalho focou diversos contextos organizacionais como instituições bancárias, empreendimentos comerciais, hospitais e órgãos públicos, prevalecendo, entretanto, as pesquisas conduzidas no setor público. Nesse sentido, são necessárias mais pesquisas no setor privado e mesmo no terceiro setor, o qual possui dinâmica e pressupostos peculiares que podem levar a resultados interessantes e a novas linhas de investigação. Quase a totalidade das pesquisas foi de natureza quantitativa, utilizando a regressão linear como principal técnica de análise de dados, o que delineia uma lacuna importante para estudos de abordagem híbrida (quali-quanti) e mesmo para abordagens e técnicas de análise mais sofisticadas como a multinível e a modelagem por equações estruturais.

O modelo conceitual adotado nesta pesquisa é o proposto por Siqueira (2008) e apresentado no Quadro 3. 
Quadro 3. Fatores de Satisfação no Trabalho

\begin{tabular}{|ll|}
\hline $\begin{array}{l}\text { Fatores da Satisfação no } \\
\text { Trabalho }\end{array}$ & Descrição \\
\hline Satisfação com Salário & $\begin{array}{l}\text { Contentamento com o que recebe como salário se comparando } \\
\text { com o quanto o indivíduo trabalha, com sua capacidade profis- } \\
\text { sional, com o custo de vida e com os esforços feitos na realização } \\
\text { do trabalho. }\end{array}$ \\
\hline $\begin{array}{l}\text { Satisfação com Colegas de } \\
\text { trabalho }\end{array}$ & $\begin{array}{l}\text { Contentamento com a colaboração, a amizade, a confiança e o } \\
\text { relacionamento mantido com os colegas de trabalho. }\end{array}$ \\
\hline Satisfação com Chefia & $\begin{array}{l}\text { Contentamento com a organização e capacidade profissional do } \\
\text { chefe, com o interesse pelo trabalho dos geridos e entendimento } \\
\text { entre eles. }\end{array}$ \\
\hline Satisfação com Promoções & $\begin{array}{l}\text { Contentamento com o número de vezes que já recebeu promoções, } \\
\text { com as garantias oferecidas, com a maneira de a empresa realizá- } \\
\text { las e com o tempo de espera por eles. }\end{array}$ \\
\hline $\begin{array}{l}\text { Satisfação com natureza do } \\
\text { trabalho }\end{array}$ & $\begin{array}{l}\text { Contentamento com o interesse despertado pelas tarefas, com a } \\
\text { capacidade de absorverem o colaborador e com a variedade das } \\
\text { mesmas. }\end{array}$ \\
\hline
\end{tabular}

Fonte: SIQUEIRA, M. M. M. Satisfação no trabalho. In: SIQUEIRA, M. M. M. (Org.). Medidas do comportamento organizacional: ferramentas de diagnóstico e de gestão. Porto Alegre: Artmed, 2008. p. 265-275.

Por fim, no que tange à relação entre políticas de GP, satisfação no trabalho e comprometimento organizacional, há um consenso na literatura internacional de que políticas e práticas de GP impactam positivamente tanto a satisfação quanto o comprometimento (GUEST, 1987; GUEST; CONWAY, 2011; KATOU, 2012). No Brasil, foi encontrado o estudo de Borges, Marques e Adorno (2006), mostrando a influência das políticas de GP tanto na satisfação quanto no comprometimento no trabalho, com uma predição maior para satisfação no trabalho, e que servirá de base para comparação com os resultados da presente pesquisa.

A partir daí, é possível estabelecer três hipóteses para a pesquisa:

Hipótese 1: As políticas de GP são preditoras do comprometimento organizacional (GUEST, 1987; GUEST; CONWAY, 2011; KATOU, 2012);

Hipótese 2: As políticas de GP são preditoras da satisfação no trabalho (GUEST, 1987; GUEST; CONWAY, 2011; KATOU, 2012);

Hipótese 3: As políticas de GP predizem mais a satisfação no trabalho que o comprometimento organizacional (BORGES; MARQUES; ADORNO, 2006).

\section{MÉTODO}

\section{Modelos da Pesquisa}

A presente pesquisa possui dois modelos. A Figura 1 apresenta o modelo de pesquisa 1, tendo como variável independente (VI) as políticas de GP em suas quatro dimensões: envolvimento; treinamento, desenvolvimento \& educação (TD\&E); condições de trabalho; e recompensas, e como variável dependente (VD), o comprometimento organizacional, mensurado em suas três bases: afetiva, calculativa e normativa. 
Figura 1. Modelo de Pesquisa 1

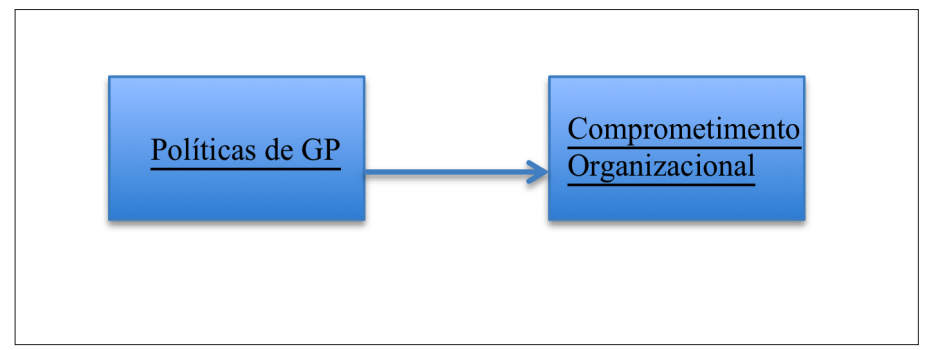

A Figura 2 apresenta o modelo de pesquisa 2, tendo como VI as políticas de GP e como VD a satisfação no trabalho que, por sua vez, será aferida pelos seus cinco fatores, que são: chefia, natureza do trabalho, colegas, salário e promoções.

Figura 2. Modelo de Pesquisa 2

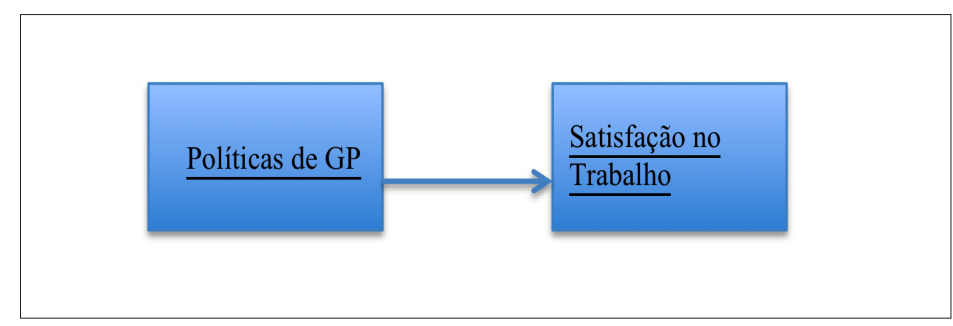

\subsection{Caracterização da pesquisa, organização e amostra}

Esta pesquisa pode ser classificada como descritiva, explicativa e confirmatória quanto aos fins; pesquisa de campo, ou survey, quanto aos meios; quantitativa quanto à sua natureza e transversal quanto ao seu horizonte temporal.

A Livraria Cultura, uma empresa familiar, com proprietários de origem alemã, foi fundada na cidade de São Paulo e completou 65 anos de atuação no mercado nacional em 2012 com 17 lojas espalhadas pelo Brasil e mais de 1.9 mil funcionários. É conhecida por possuir o maior acervo de títulos do mercado, ao lado do propalado atendimento ao cliente aliado a entretenimento de alta qualidade. A empresa possui operações em quase todas as regiões brasileiras, com exceção da região norte, com as atividades de Gestão de Pessoas centralizadas em São Paulo, que dita políticas e práticas padronizadas para todas as filiais.

A empresa preza por gestão participativa em todas as suas lojas, ou seja, todos os colaboradores podem contribuir para as tomadas de decisões no seu âmbito de trabalho. Esse modelo de gestão está diretamente ligado às políticas de GP da empresa que zelam, em primeiro lugar, pelo crescimento e formação de talentos. Por isso, as oportunidades na empresa sempre são primeiramente focadas internamente. Outro ponto importante é a formação de novos colaboradores na empresa por meio de um Programa de Integração Cultura (PIC), em que os novos talentos passam por uma imersão em treinamentos que Ihes possibilitem obter todas as ferramentas e conhecimentos necessários para uma carreira de sucesso na Livraria Cultura. Juntamente com essa formação, feedbacks periódicos permitem a esses colaboradores um direcionamento claro de seu desempenho e crescimento.

Para todos os seus colaboradores, a empresa dispõe de uma série de benefícios diferenciados como parcerias com empresas de lazer (cinema, parque de diversão, SESC, etc.) e de saúde (academias). Esses benefícios se incorporam ao pacote de benefícios da empresa, que conta também com auxílio educação de acordo com a performance de seus colaboradores. Mediante uma avaliação anual de perfil e performance, qualquer colaborador pode pleitear uma ajuda de custo de até $80 \%$ 
para cursos de idiomas, graduação ou pós-graduação. Por ser uma empresa que promove a cultura, internamente há também incentivos para a busca do conhecimento com concursos e jogos que premiam seus colaboradores com diversos prêmios. Aliado a isso, todos os colaboradores podem usufruir do benefício de empréstimo de livros, por meio do qual todo mês cada colaborador pode retirar 5 livros para empréstimo. Isso permite que todos que trabalham na Livraria Cultura também possam crescer culturalmente e partilhar dessas experiências com os clientes.

Compuseram a população da pesquisa os 139 colaboradores da Livraria Cultura do Shopping Casa Park, em Brasília. A amostra foi caracterizada como não probabilística por conveniência. A empresa exigiu que não houvesse informações sociodemográficas que pudessem identificar os respondentes. Do total de 139 questionários distribuídos, 97 foram devolvidos, representando cerca de $70 \%$ da população pesquisada.

Para se utilizar técnicas de análise multivariada como regressão linear é importante selecionar uma amostra mínima que tenha poder estatístico maior que 0,80 (COHEN, 1992). Por meio do programa GPower 3.1 e considerando que a variável preditora (políticas de GP) possui 4 fatores (envolvimento; treinamento, desenvolvimento e educação; condições de trabalho; e recompensas), obteve-se a amostra mínima, com a =0,05, ES médio e 4 preditores, de 85 sujeitos. Ainda, como apontado por Tabachnick e Fidell (2007), calcula-se o tamanho da amostra para procedimentos estatísticos como correlações e regressões múltiplas por meio da regra ' $N \geq 50+8 m^{\prime}$, onde $N$ é o tamanho da amostra e ' $m$ ' é o número de variáveis independentes ou preditoras (VI 's ou VP's) do modelo. No modelo desta pesquisa, tem-se 4 VI's (fatores de políticas de GP), o que resulta em uma amostra mínima recomendada de 82 sujeitos.

O processo de tratamento dos dados iniciou-se com a relação da análise de dados por meio da distribuição de frequências (média, desvio padrão, variância, mínimo e máximo), demonstrando assim a coerência dos dados. O tratamento em relação aos dados faltantes não se fez necessário, visto que todos os respondentes entregaram os questionários devidamente preenchidos. Em seguida, foi realizada a análise de verificação de outliers, por meio da distância denominada Mahalonobis, conforme recomendado por Tabachnick e Fidell (2007). O resultado apontou 11 outliers que foram retirados da amostra. Após esses processos, a amostra final contou com 86 participantes, ainda atendendo aos critérios de Cohen (1992) e de Tabachnick e Fidell (2007).

\section{Instrumentos de pesquisa}

A respeito da mensuração da percepção das políticas de GP, foi utilizada a escala de Demo (2008), Escala de Percepção de Políticas de Gestão de Pessoas (EPPGP), com 19 itens, distribuídos nos 4 fatores mostrados no Quadro 1, com índices de confiabilidade (a de Cronbach), variando entre 0,72 e 0,88 . Para medir o comprometimento organizacional, foram utilizadas as escalas de Siqueira $(1995,2000)$ para identificação do comprometimento organizacional afetivo (ECOA - 5 itens e índice de confiabilidade de 0,93 ), comprometimento organizacional calculativo (ECOC - 15 itens e índice de confiabilidade de 0,92 ) e comprometimento organizacional normativo (ECON - 7 itens e índice de confiabilidade de 0,86). Por fim, no que tange à avaliação da satisfação no trabalho, foi utilizada a versão reduzida da Escala de Satisfação no Trabalho (EST) de Siqueira (1995), com 15 itens distribuídos em 5 fatores, conforme apresentado no Quadro 3 e índices de confiabilidade entre 0,77 e 0,90. Todas são escalas no modelo Likert de 5 pontos.

\section{Procedimentos de coleta e análise dos dados}

Inicialmente, foi solicitada autorização à direção e gestão da área de Recursos Humanos da Livraria Cultura em São Paulo para realização da pesquisa. Posteriormente, foram distribuídos os questionários para cada colaborador, em mãos e por e-mail. Vale ressaltar que, atendendo ao pedido da empresa, nenhuma informação de caráter pessoal/profissional foi solicitada aos respondentes no afã de garantir a fidedignidade e a confidencialidade das informações.

Foram feitas, em um primeiro momento, análises estatísticas descritivas para identificar a percepção das políticas de gestão de pessoas, o comprometimento organizacional e a satisfação no 
trabalho. Em seguida, foi utilizada a regressão múltipla do tipo padrão, uma vez que ela é utilizada para estudos explicativos, nos quais se pretende investigar relações conhecidas entre as variáveis com a pretensão de identificar o poder preditivo de cada variável independente de forma individual. No caso deste estudo, a regressão padrão tem por objetivo identificar quais as políticas de GP são as melhores preditoras dos construtos comprometimento organizacional e satisfação no trabalho. Em um segundo momento, foi utilizada regressão múltipla do tipo hierárquica para confirmar os resultados do estudo realizado no Brasil investigando as mesmas relações (BORGES; MARQUES; ADORNO, 2006).

\section{RESULTADOS}

A Tabela 1 sintetiza as estatísticas descritivas para todas as variáveis estudadas

Tabela 1. Estatísticas Descritivas

\begin{tabular}{|c|c|c|}
\hline Variável & Média & Desvio-Padrão \\
\hline Política de Envolvimento & 3,82 & 0,67 \\
\hline Política de TD\&E & 3,07 & 0,85 \\
\hline Política de Condições de Trabalho & 4,17 & 0,49 \\
\hline Política de Recompensas & 3,36 & 0,89 \\
\hline Comprometimento Afetivo & 3,78 & 0,76 \\
\hline Comprometimento Calculativo & 2,81 & 0,60 \\
\hline Comprometimento Normativo & 2,52 & 0,64 \\
\hline Satisfação com Salário & 2,78 & 1,06 \\
\hline Satisfação com Colegas de Trabalho & 4,13 & 0,52 \\
\hline Satisfação com a Chefia & 3,78 & 0,91 \\
\hline Satisfação com Promoções & 2,92 & 0,91 \\
\hline Satisfação com a Natureza do Trabalho & 3,81 & 0,67 \\
\hline
\end{tabular}

Os resultados mostraram que as políticas de GP, de maneira geral, estão sendo percebidas pelos colaboradores da livraria, com destaque para as condições de trabalho. O maior compromisso dos colaboradores com a organização é o afetivo, e sua satisfação no trabalho pode ser explicada, principalmente, pela satisfação com colegas e com a natureza das tarefas que desenvolvem. Foram realizadas oito regressões múltiplas padrão, uma para cada variável dependente (3 fatores do comprometimento organizacional e 5 fatores da satisfação no trabalho). As suposições para uso da regressão (linearidade do fenômeno, homoscedasticidade, independência dos termos de erro e normalidade da distribuição dos termos de erro) foram analisadas por meio de gráficos de resíduos, gráficos de probabilidade normal e testes estatísticos. Por fim, as análises de multicolinearidade e singularidade não apresentaram problemas para a amostra pesquisada, ou seja, os valores de tolerance foram superiores a 0,1 e de variance inflation factor (VIF) inferiores a 10,0 (MYERS, 1990). A Tabela 2 sumariza os resultados das regressões múltiplas dos dois modelos de pesquisa propostos. 
Tabela 2. Regressões múltiplas: resultados dos modelos

\begin{tabular}{|c|c|c|c|c|c|}
\hline VD & VI & $\begin{array}{l}\mathrm{R} \\
\left(\mathrm{R}^{2}\right)\end{array}$ & Variáveis & $\boldsymbol{\beta}$ & $\begin{array}{l}\text { Teste Estatís- } \\
\text { tico }\end{array}$ \\
\hline $\begin{array}{l}\text { Comprometimento Orga- } \\
\text { nizacional Afetivo }\end{array}$ & $\begin{array}{l}\text { Políticas de } \\
\text { GP }\end{array}$ & $\begin{array}{l}0.757 \\
(0.574)\end{array}$ & $\begin{array}{l}\text { Envolvimento } \\
\text { Recompensas }\end{array}$ & $\begin{array}{l}0.543^{* *} \\
0.308^{* *}\end{array}$ & $\mathrm{~F}=55.137 * *$ \\
\hline $\begin{array}{l}\text { Comprometimento Orga- } \\
\text { nizacional Calculativo }\end{array}$ & $\begin{array}{l}\text { Políticas de } \\
\text { GP }\end{array}$ & $\begin{array}{l}0.429 \\
(0.184)\end{array}$ & Recompensas & $0.429 * *$ & $\mathrm{~F}=18.672 * *$ \\
\hline $\begin{array}{l}\text { Comprometimento Orga- } \\
\text { nizacional Normativo }\end{array}$ & $\begin{array}{l}\text { Políticas de } \\
\text { GP }\end{array}$ & $\begin{array}{l}0.340 \\
(0.116)\end{array}$ & Recompensas & $0.340 * *$ & $\mathrm{~F}=10.861 * *$ \\
\hline Satisfação com Salário & $\begin{array}{l}\text { Políticas de } \\
\text { GP }\end{array}$ & $\begin{array}{l}0.767 \\
(0.588)\end{array}$ & Recompensas & $0.767 * *$ & $\begin{array}{l}\mathrm{F} \\
118.340 * *\end{array}=$ \\
\hline Satisfação com Colegas & $\begin{array}{l}\text { Políticas de } \\
\text { GP }\end{array}$ & Não hou & preditor no $\mathrm{mc}$ & & \\
\hline Satisfação com Chefia & $\begin{array}{l}\text { Políticas de } \\
\text { GP }\end{array}$ & $\begin{array}{l}0.567 \\
(0.322)\end{array}$ & Envolvimento & $0.567 * *$ & $\mathrm{~F}=39.427 * *$ \\
\hline Satisfação com Promoções & $\begin{array}{l}\text { Políticas de } \\
\text { GP }\end{array}$ & $\begin{array}{l}0.683 \\
(0.466)\end{array}$ & $\begin{array}{l}\text { Recompensas } \\
\text { TD\&E } \\
\text { Envolvimento }\end{array}$ & $\begin{array}{l}0.294 * * \\
0.293 * * \\
0.227 * *\end{array}$ & $\mathrm{~F}=23.560 * *$ \\
\hline $\begin{array}{l}\text { Satisfação com Natureza do } \\
\text { Trabalho }\end{array}$ & $\begin{array}{l}\text { Políticas de } \\
\text { GP }\end{array}$ & $\begin{array}{l}0.683 \\
(0.466)\end{array}$ & $\begin{array}{l}\text { Envolvimento } \\
\text { Recompensas }\end{array}$ & $\begin{array}{l}0.508^{* *} \\
0.255^{* *}\end{array}$ & $\mathrm{~F}=35.798 * *$ \\
\hline
\end{tabular}

Nota: $* * p<0.001$

Os resultados das análises de regressão apontaram duas principais políticas de GP como melhores preditoras do comprometimento organizacional e da satisfação no trabalho, em cada uma de suas dimensões: políticas de envolvimento e políticas de recompensas. A política de envolvimento é melhor preditora do comprometimento organizacional afetivo $(\beta=0.543)$, da satisfação no trabalho com chefia $(\beta=0.567)$ e da satisfação no trabalho com natureza no trabalho $(\beta=0.508)$. A política de recompensas influencia mais fortemente o comprometimento organizacional calculativo $(\beta=0.429)$, o comprometimento organizacional normativo $(\beta=0.340)$, a satisfação no trabalho com salário $(\beta=0.767)$ e a satisfação no trabalho com promoções $(\beta=0.294)$. Quanto ao estudo confirmatório, realizado por meio de regressão hierárquica, foi tomado como base para comparação o estudo de Borges, Marques e Adorno (2006). Este estudo investigou as relações entre políticas de GP, comprometimento e satisfação, utilizando medidas diferentes das utilizadas na presente pesquisa, mostrando que as políticas de GP são preditoras do comprometimento organizacional e mais ainda da satisfação no trabalho. A presente pesquisa confirmou tais resultados e a hipótese 3, conforme apresenta a Tabela 3.

Tabela 3. Resultados Regressão Hierárquica

\begin{tabular}{lll}
\hline Variáveis & $\mathrm{R}^{2}$ (presente pesquisa) & $\mathrm{R}^{2}$ (Borges, Marques e Adorno) \\
\hline Comprometimento Organizacional & $0.52 * *$ ou $52 \%$ & $0.26 *$ ou $26 \%$ \\
\hline Satisfação no Trabalho & $0.64 * *$ ou $64 \%$ & $0.73 *$ ou $73 \%$ \\
\hline
\end{tabular}

Nota: $* p<0.05 e^{* *} p<0.001$ 
De acordo com Cohen (1992), a interpretação que se dá para a significância estatística do coeficiente de determinação de uma regressão $\left(R^{2}\right)$ no âmbito das ciências comportamentais considera $2 \%$ como um pequeno efeito, $13 \%$ como médio efeito e a partir de $26 \%$, grande efeito. Constata-se, assim, pelos resultados obtidos, que as políticas de GP são fortes preditoras tanto do comprometimento organizacional, explicando $52 \%$ do construto, quanto da satisfação no trabalho, contribuindo com aproximadamente $64,5 \%$ para a explicação de sua variabilidade. Por conseguinte, as hipóteses 1 e 2 do estudo também foram confirmadas.

\section{DISCUSSÃO}

Segundo os resultados obtidos, pode-se afirmar que a política de condições de trabalho é a mais percebida, ou seja, os colaboradores da Livraria Cultura percebem os esforços engendrados pela organização para promover sua saúde, segurança e bem-estar no trabalho. Por outro lado, as demais políticas são pouco percebidas pelos colaboradores. As políticas que obtiveram médias em torno de 3 (ponto neutro da escala), recompensas e TD\&E, não são consideradas bem percebidas. É possível, portanto, inferir que a promoção de tais práticas pela organização não é percebida pelos colaboradores. É provável que a falta de percepção de tais políticas resulte na não concretização de resultados que visam à melhora do desempenho pessoal e organizacional. É possível também especular a respeito da eficiência da comunicação organizacional em relação às três políticas mencionadas, ou mesmo sobre o uso devido de recursos para a realização delas.

Tais achados confirmam os obtidos por Demo et al. (2012), ao identificar políticas de GP em uma grande amostra de empresas brasileiras públicas e privadas, utilizando o mesmo instrumento da presente pesquisa. A política de condições de trabalho foi a mais percebida nas organizações privadas e as de TD\&E e recompensas as menos percebidas. Isso sinaliza que os gestores brasileiros precisam atentar para o desenvolvimento de seus colaboradores. Adicionalmente, práticas de remuneração e incentivos precisam ser retrabalhadas de forma a garantir que a relação esforço-recompensa esteja clara entre todos os colaboradores, a fim de evitar atitudes retaliativas e otimizar a efetividade.

Os resultados também indicaram que os colaboradores da livraria estão comprometidos principalmente na base afetiva, seguida da calculativa e da normativa. Revela-se, então, que eles permanecem na empresa porque querem, pois estabelecem uma relação afetiva com ela. Os colaboradores se identificam com as metas e os valores da organização e se envolvem com papéis de trabalho que permitam a realização dos objetivos organizacionais. Assim, como grande parte dos funcionários são universitários que trabalham temporariamente para custear seus estudos, somado à parca percepção da política de recompensas, sua avaliação de custos com um possível desligamento não parece elevado, explicando seu baixo compromisso calculativo. Tampouco se sentem pressionados a agir de maneira a cumprir, por dever moral ou ético, os objetivos da organização, o que acontece em empresas tradicionais nas quais os funcionários constroem longas carreiras, ou seja, possuem baixo compromisso normativo.

No que tange à satisfação no trabalho, os colaboradores da Livraria Cultura se sentem satisfeitos principalmente com as relações de amizade e confiança com seus colegas, percebendo, então, alta qualidade no ambiente social. Como já dito, grande parte dos colaboradores são jovens universitários e muitos estendem seu convívio para além do local de trabalho. Ademais, eles se mostram também satisfeitos com a diversidade e o dinamismo das tarefas realizadas e com o interesse que elas despertam. Uma das razões pode ser que, em se tratando de prestação de serviço ao cliente, as situações vivenciadas em loja são imprevisíveis, traduzindo-se em recorrentes novos desafios. Por último, é identificada a satisfação quanto ao relacionamento com a chefia, o interesse dela pelos colaboradores e o reconhecimento de suas capacidades profissionais. A gestão participativa propalada pela empresa pode ser um fator importante para explicar tal resultado.

Respondendo a principal questão desta pesquisa, a saber, se as percepções de políticas de GP são preditoras do comprometimento organizacional e da satisfação no trabalho, a resposta é afirmativa. As hipóteses 1 e 2 foram confirmadas, uma vez que as políticas de GP apresentaram-se como forte preditoras do comprometimento organizacional e da satisfação no trabalho, validando os achados dos estudos de Guest (1987), Guest e Conway (2011) e Katou (2012). A hipótese 3 também encontrou respaldo teórico, confirmando os resultados obtidos por Borges, Marques e Adorno (2006), ao afirmarem que as políticas de GP predizem mais a satisfação que o comprometimento. 
Em relação às bases do comprometimento, a política de envolvimento foi a principal preditora e relacionou-se positivamente com o comprometimento organizacional afetivo, definido como o processo de identificação do indivíduo com os objetivos e os valores da organização (BASTOS, 1998). Por isso, quanto mais os colaboradores percebem as práticas de reconhecimento profissional, relacionamento e interação de pessoas na organização, participação na condução de processos decisórios e comunicação organizacional, mais estarão comprometidos afetivamente com a empresa, ou seja, haverá maior identificação das pessoas com os objetivos e os valores da organização. Seria o equivalente científico do jargão popular "vestir a camisa da empresa".

A política de recompensas foi a única preditora relacionando-se positivamente com o comprometimento calculativo, que tem por definição o produto das recompensas e os custos percebidos pelo empregado na condição de integrante da organização (BASTOS, 1998). Ou seja, maiores investimentos em políticas de recompensas contribuirão para uma relação positiva de custos e benefícios financeiros para o colaborador, fazendo-o permanecer na empresa. As recompensas também foram a única preditora do comprometimento normativo, apresentando associação positiva com esta variável que tem por definição o conjunto de pressões de normas sociais que definem o vínculo do empregado com a empresa (BASTOS, 1998). Em outras palavras, maiores investimentos em políticas de recompensas farão com que o colaborador sinta o dever moral de agir de maneira coerente com os objetivos organizacionais.

Quanto aos fatores de satisfação no trabalho, a política de recompensas foi a principal preditora, associando-se positivamente com a satisfação, com o salário e com promoções. Naturalmente, quanto maior a percepção de recompensas, maior o contentamento com o que se recebe como salário se comparado com o quanto o indivíduo trabalha, com a sua capacidade profissional, com o custo de vida, com os esforços feitos na realização do trabalho, com o número de vezes que já recebeu promoções, com as garantias oferecidas e com a maneira de a empresa realizá-las (SIQUEIRA, 2008).

Já a política de envolvimento apresentou relação positiva, sendo a principal preditora da satisfação com a chefia e com a natureza do trabalho. Desta forma, quanto mais os colaboradores percebem as práticas de reconhecimento profissional, relacionamento e promoção da interação entre as pessoas na organização, participação na condução de processos decisórios e comunicação organizacional, mais estarão satisfeitos com seus gestores. Na mesma linha, práticas de envolvimento produzirão satisfação com a natureza do trabalho, definida como o contentamento com o interesse despertado pelas tarefas, com a capacidade de absorverem o colaborador, e com a variedade das atividades (SIQUEIRA, 2008). A satisfação com colegas foi a única variável não explicada por nenhuma das políticas de GP propostas no modelo da pesquisa, indicando que outras variáveis não contempladas aqui precisam ser investigadas em estudos futuros.

De maneira geral, relações entre políticas de GP e comprometimento organizacional já foram anteriormente estudadas (BARROS; SCHEIBLE, 2008; CANÇADO; MORAES; SILVA, 2006), assim como entre políticas de GP e satisfação (DESSLER, 2002; GUEST, 1987; MATHIS; JACKSON, 2003), verificando os mesmos resultados obtidos na presente pesquisa: as políticas de GP são preditoras tanto do comprometimento organizacional quanto da satisfação no trabalho. No que tange à realidade da Livraria Cultura, foco do estudo, quanto às políticas de GP, destacaram-se as políticas de condições de trabalho e envolvimento na percepção dos colaboradores. Além disso, a título de informação para a empresa, os colaboradores demonstraram índices bons de satisfação com a gerência, com os colegas e com a natureza do trabalho. A empresa conta ainda com trabalhadores comprometidos principalmente por fatores afetivos, tratando-se de uma informação relevante que deve ser analisada e utilizada em prol dos objetivos e das metas organizacionais.

Por fim, pode-se considerar que os resultados obtidos são consistentes e salientam, conforme Siqueira e Gomide Júnior (2004), a relevância de estudar as relações existentes no ambiente de trabalho, a fim de permitir que a organização atinja seus objetivos de produtividade e eficiência, como também considere a satisfação das aspirações e das necessidades individuais das pessoas que as compõem.

\section{CONTRIBUIÇÕES, LIMITAÇÕES E RECOMENDAÇÕES PARA FUTURAS PESQUISAS}

Quanto às contribuições acadêmicas, os resultados confirmam os achados de estudos internacionais e nacionais, contribuindo com a formação de um arcabouço teórico mais consistente 
no que tange às relações entre estas variáveis nas áreas de Psicologia Organizacional e Gestão de Pessoas e, mormente, incentivando estudos relacionais que mesclem variáveis oriundas de diferentes áreas do conhecimento, fomentando a multidisciplinaridade. Ademais, o estudo apresentou uma nova maneira de avaliar e medir as políticas de GP nas organizações brasileiras, considerando a escassez na literatura de medidas desta natureza. Em relação às contribuições gerenciais, os resultados por ora engendrados podem ser vistos como um diagnóstico em que os gestores organizacionais poderão compreender com mais profundidade e abrangência como as variáveis se relacionam, de sorte a fortalecer o compromisso dos empregados e elevar sua satisfação com o trabalho. Além disso, poderia ser utilizado como uma ferramenta diagnóstica para identificar áreas de GP, em que melhorias específicas se fazem necessárias.

Não obstante o estudo ter alcançado seus objetivos, há limitações que precisam ser destacadas no afã de engendrar uma agenda de pesquisas futuras. Pesquisas que usam dados transversais podem comprometer a generalização dos resultados. Portanto, é altamente recomendável que estudos futuros utilizem dados longitudinais ou mesmo amostras de outras organizações com naturezas diferentes, como organizações públicas e do terceiro setor e, além disso, empresas operando em outros setores da indústria, uma vez que características do ramo de atuação podem determinar alguns comportamentos no ambiente de trabalho. A pesquisa também foi conduzida em uma única organização, portanto, fatores relacionados à cultura organizacional podem ter produzido vieses de interpretação dos itens das escalas utilizadas.

Ainda, mesmo que as políticas de GP da empresa estudada sejam padronizadas em todo o território nacional, seria interessante investigar outras filiais, considerando que fatores culturais locais podem produzir resultados diferentes. Foi inaugurada em Brasília, recentemente, a segunda filial da Livraria Cultura, no Shopping Iguatemi, com público-alvo diferenciado, o que pode trazer achados também peculiares. Variáveis como o bem-estar no trabalho e a confiança do empregado na organização também podem ser integradas aos modelos propostos, já que foi comprovada a influência de políticas de GP em ambas variáveis (HORTA; DEMO; ROURE, 2012; MARIOTTI; SOUZA, 2005; NISHII; LEPAK; SCHNEIDER, 2008; TURNER; HUEMANN; KEEGAN, 2008). Na mesma linha, indicadores de desempenho organizacional podem ser incorporados ao modelo, uma vez que há evidência empírica e teórica de relações entre políticas de GP e desempenho (BOSELIE; DIETZ; BOON, 2005; EZZAMEL; LILLEY; WILLMOTT, 1996; GUEST; HOQUE, 1994; MENEZES; WOOD; GELADE, 2010; SUBRAMONY, 2009).

\section{CONCLUSÕES}

O presente estudo alcançou o seu objetivo precípuo ao mostrar relações positivas entre políticas de GP, comprometimento organizacional e satisfação no trabalho. Políticas de GP são fortes preditoras do comprometimento e mais ainda da satisfação, sustentando as hipóteses propostas pela pesquisa. Adicionalmente, foram identificados os melhores preditores do comprometimento e da satisfação e destacaram-se as políticas de envolvimento e recompensas. Depreende-se daí que os gestores de GP devem primar por práticas de participação, comunicação, reconhecimento e relacionamento, a fim de envolver mais os colaboradores e melhorar seu compromisso afetivo e sua satisfação com a chefia e com o escopo do trabalho. Adicionalmente, práticas de remuneração e incentivos se traduzirão em maior comprometimento calculativo e normativo, além de maior satisfação com questões salariais.

Por fim, tais recomendações não pretendem ser conclusivas ou limitantes, mas traduzem-se em um convite para a realização constante de pesquisas, no intuito de construir um arcabouço teórico consistente para promover o avanço progressivo do conhecimento teórico-empírico sobre políticas de GP, comprometimento e satisfação nas organizações brasileiras.

\section{REFERÊNCIAS}

ALLEN, N. J.; MEYER, J. P. The measurement and antecedents of affective, continuance and normative commitment to the organization. Journal of Occupational Psychology, v. 63, n. 2, p. 1-18, 1990.

ARMSTRONG, M. Armstrong's handbook of human resource management practice. 11. ed. London: Kogan Page, 2009. 
BARROS, A. R. O.; SCHEIBLE, A. C. F. Comprometimento organizacional: um estudo de suas relações com práticas de gestão e intenção de permanência. In: EnANPAD, 32., 2008, Rio de Janeiro. Anais... Rio de Janeiro: ANPAD, 2008. 1 CD.

BASTOS, A. V. B. Comprometimento no trabalho: contextos em mudança e os rumos da pesquisa neste domínio. In: EnANPAD, 22., 1998, Foz do Iguaçu. Anais... Foz do Iguaçu: ANPAD, 1998.

BEAUVALLET, G.; HOUY, T. Research on HRM and lean management: a literature survey. The International Journal of Human Resources Development and Management, v. 10, n. 1, p. 14-33, 2010.

BERNSTORFF, V. H. A intensificação do trabalho, a satisfação profissional e seus efeitos sobre o estresse ocupacional. In: EnANPAD, 31., 2007, Rio de Janeiro. Anais... Rio de Janeiro: ANPAD, 2007a.

A satisfação profissional e as influências da organização do trabalho. In: EnANPAD, 31., 2007, Rio de Janeiro. Anais... Rio de Janeiro: ANPAD, 2007b.

BERNSTORFF, V. H.; DAL ROSSO, S. O absenteísmo ao trabalho como forma de resistência individual à intensificação do trabalho, à insatisfação profissional e ao estresse ocupacional. In: EnANPAD, 32., 2008, Rio de Janeiro. Anais... Rio de Janeiro: ANPAD, 2008.

BORGES, R. S. G.; MARQUES, A. L.; ADORNO, R. D. Investigando as relações entre políticas de RH, comprometimento organizacional e satisfação no trabalho. Revista de Práticas Administrativas, Maringá, v. 2 , n. 1 , p. 59-72, set./out. 2006.

BOSELIE, P.; DIETZ, G.; BOON, C. Comunalities and contradictions in HRM and performance research. Human Resource Management Journal, v. 15, n. 3, p. 67-94, 2005.

BOXALL, P.; PURCELL, J.; WRIGHT, P. Human resource management: scope, analysis and significance. In: BOXALL, P.; PURCELL, J.; WRIGHT, P. (Orgs.). The Oxford handbook of human resource management. New York: Oxford University Press, 2007. p. 1-16.

BUTLER, M. C.; EHRLICH, S. B. Positional influences on job satisfaction and job performance: a multivariate, predictive approach. Psychological Reports, v. 69, n. 3, p. 855-865, Dec. 1991.

CAMPOS, C. V. A.; MALIK, A. M. Satisfação no trabalho e rotatividade dos médicos do Programa de Saúde da Família. Revista de Administração Pública, Rio de Janeiro, v. 42, n. 2, p. 347-368, mar./abr. 2008.

CANÇADO, V. L.; MORAES, L. F. R.; SILVA, E. M. Comprometimento organizacional e práticas de gestão de recursos humanos: o caso da empresa XSA. Revista de Administração Mackenzie, v. 7, n. 3, p. 11-37, 2006.

CHANG JUNIOR, J.; SANTOS, S. B. S.; SILVA, A. F.; CHANG, M. S.; NOGUEIRA, A. A. Variáveis antecedentes ao comprometimento organizacional afetivo e sua relação com o desempenho: uma abordagem estratégica baseada no modelo Resource Based View - RBV. In: EnANPAD, 31., 2007, Rio de Janeiro. Anais... Rio de Janeiro: ANPAD, 2007.

COELHO JUNIOR, F. A.; MOURA, C. F. Revalidação de escala de satisfação no trabalho. In: EnANPAD, 32. 2008, Rio de Janeiro. Anais... Rio de Janeiro: ANPAD, 2008.

COHEN, J. A power primer. Psychological Bulletin, v. 112, n. 1, p. 155-159, 1992.

CÚNICO, L. H. B.; ZAMPIER, M. A. Predição de satisfação de funcionários de uma rede de lojas do comércio varejista através da aplicação de técnicas em Data Mining. In: EnANPAD, 32., 2008, Rio de Janeiro. Anais... Rio de Janeiro: ANPAD, 2008.

DEMO, G. Comprometimento no trabalho: uma síntese do estado da arte e uma revisão da produção nacional. rPOT - Revista Psicologia, Organizações e Trabalho, Brasília, v. 3, n. 2, p. 185-213, jul./dez. 2003.

DEMO, G. Desenvolvimento e validação da Escala de Percepção de Políticas de Gestão de Pessoas (EPPGP). Revista de Administração Mackenzie, São Paulo, v. 9, n. 6, p. 77-101, 2008.

DEMO, G.; FOGAÇA, N.; NUNES, I.; EDREI, L.; FRANCISCHETO, L. Políticas de gestão de pessoas no novo milênio: cenário dos estudos publicados nos periódicos da área de administração entre 2000 e 2010. Revista de Administração Mackenzie, São Paulo, v. 12, n. 5, p. 15-42, set./out. 2011.

DEMO, G.; NUNES, I.; FOGAÇA, N.; BARCELOS, B.; ROURE, P. Gestão de pessoas. In: DEMO, G. (Org.). Políticas de gestão de pessoas em organizações: estado da arte, produção nacional, agenda de pesquisa, medidas e estudos relacionais. São Paulo: Atlas, 2012. p. 3-48. 
DESSLER, G. Human resource management. 9. ed. New Jersey: Prentice Hall, 2002.

EZZAMEL, M.; LILLEY, S.; WILKINSON, A.; WILLMOTT, H. Practices and practicalities in human resource management. Human Resource Management Journal, v. 6, n. 1, p. 63-80, 1996.

GUEST, D. Human resource management and industrial relations. Journal of Management Studies, $v$. 24, n. 5, p. 503-521, 1987.

GUEST, D.; CONWAY, N. The impact of HR practices, HR effectiveness and a 'strong HR system' on organisational outcomes: a stakeholder perspective. The International Journal of Human Resource Management, v. 22, n. 8, p. 1686-1702, 2011.

GUEST, D.; HOQUE, K. Yes, personnel does make a difference. Personnel Management, v. 26, n. 11, p. 40-43, 1994.

HAZAN, C.; SHAVER, P. R. Love and work: an attachment theoretical perspective. Journal of Personality and Social Psychology, v. 59, n. 2, p. 270-280, Aug. 1990.

HELLMAN, C. M. Job satisfaction and intent to leave. Journal of Social Psychology, v. 137, n. 6, p. 677-689, 1997.

HORTA, P.; DEMO, G.; ROURE, P. Políticas de gestão de pessoas, confiança e bem-estar: estudo em uma multinacional. Revista de Administração Contemporânea, Rio de Janeiro, v. 16, n. 4, art. 4, p. 566585, jul./ago. 2012.

KATOU, A. A. Investigating reverse causality between human resource management policies and organizational performance in small firms. Management Research Review, v. 35, n. 2, p. 134-156, 2012.

KRAUSZ, M.; KOSLOWSKY, M.; EISER, A. Distal and proximal influences on turnover intentions and satisfaction: support for a withdrawal progression theory. Journal of Vocational Behavior, v. 52, n. 1, p. 59-71, Feb. 1998.

LEGGE, K. Human resource management. In: ACKROYD, S.; BATT, R.; THOMPSON, P.; TOLBERT, P. S. (Eds.). The Oxford handbook of work and organization. New York: Oxford University Press, 2006. p. 220-241.

MARINHO, M. S. C. Satisfação no trabalho: uma revisão conceitual para a análise empírica. Ciência e Cultura, v. 40, n. 3, p. 312-322, 1988

MARIOTTI, D. F.; SOUZA, Y. S. Relações de confiança na dinâmica de uma organização. In: EnANPAD, 29. 2005, Brasília. Anais... Brasília: ANPAD, 2005.

MARTINEZ, M. C. As relações entre a satisfação com aspectos psicossociais no trabalho e a saúde do trabalhador. 2002. 255 f. Dissertação (Mestrado em Saúde Ambiental) - Faculdade de Saúde Pública da Universidade de São Paulo, São Paulo, 2002.

MATHIS, R. L.; JACKSON, J. H. Human resource management. 10. ed. Ohio: South-Western/Thomson, 2003.

MEDEIROS, C. A. F.; ALBUQUERQUE, L. G.; SIQUEIRA, M.; MARQUES, G. M. Comprometimento organizacional: o estado da arte da pesquisa no Brasil. In: EnANPAD, 26., 2002, Salvador. Anais... Salvador: ANPAD, 2002. 1 CD.

MENEZES, L. M.; WOOD, S.; GELADE, G. The integration of human resource and operation management practices and its link with performance: a longitudinal latent class study. Journal of Operations Management, v. 28, n. 6, p. 455-471, 2010.

MEYER, J. P.; ALLEN, N. J.; SMITH, C. A. Commitment to organizations and occupations: extension and test of a three-component conceptualization. Journal of Applied Psychology, v. 78, n. 4, p. 538-551, 1993.

MOWDAY, R. T.; PORTER, L. W.; STEERS, R. M. Employee-organization linkages - the psychology of commitment, absenteeism and turnover. New York: Academic Press, 1982.

MYERS, R. Classical and modern regression with applications. 2. ed. Boston, MA: Duxbury, 1990.

NISHII, L. H.; LEPAK, D. P.; SCHNEIDER, B. Employee attributions of the "Why" of HR practices: their effects on employee attitudes and behaviors, and customer satisfaction. Personnel Psychology, v. 61, n. 3, p. 503-545, 2008 
PFEFFER, J. Building sustainable organizations: the human factor. The Academy of Management Perspectives, v. 24, n. 1, p. 34-45, 2010.

PUENTE-PALACIOS, K. E.; BORGES-ANDRADE, J. E. O efeito da interdependência na satisfação de equipes trabalho: um estudo multinível. Revista de Administração Contemporânea, Curitiba, v. 9, n. 3, jul./set. 2005.

REGO, A.; CUNHA, M. P.; SOUTO, S. Espiritualidade nas organizações e comprometimento organizacional. RAE-Eletrônica, v. 6, n. 2, art. 12, p.1-27, jul./dez. 2007.

RIBEIRO, J. A. Comprometimento organizacional e percepção de justiça: um estudo sobre a concessão de remuneração e benefícios diferenciados a dois grupos de uma mesma empresa. In: EnANPAD, 32., 2008, Rio de Janeiro. Anais... Rio de Janeiro: ANPAD, 2008.

SANT'ANNA, A. S.; MORAES, L. F. R.; KILIMNIK, Z. M. Competências individuais, modernidade organizacional e satisfação no trabalho: um estudo de diagnóstico comparativo. RAE - eletrônica, v. 4, n. 1, Art. 1, p. 1-23, jan./jul. 2005.

SCHIRRMEISTER, R.; NUNES, L. A. P.; LIMONGI-FRANÇA, A. C.; GONÇALVES, A. F. As relações de trabalho no porto de Santos: um estudo sobre a qualidade de vida no trabalho e o comprometimento organizacional no contexto da modernização dos portos. In: EnANPAD, 32., 2008, Rio de Janeiro. Anais... Rio de Janeiro: ANPAD, 2008.

SIQUEIRA, M. M. M. Antecedentes de comportamento de cidadania organizacional: análise de um modelo pós-cognitivo. 1995. 267 p. Tese (Doutorado em Psicologia) - Instituto de Psicologia da Universidade de Brasília, Brasília, 1995.

Análise de três medidas de comprometimento organizacional: afetivo, calculativo e normativo. In: Conferência Internacional de Avaliação Psicológica, 8., 2000. Anais... Belo Horizonte: Pontifícia Universidade Católica de Minas Gerais, 2000. p. 40-41.

. Comprometimento organizacional. In: SIQUEIRA, M. M. M. (Org.). Medidas do comportamento organizacional: ferramentas de diagnóstico e de gestão. Porto Alegre: Artmed, 2008. p. 49-95.

Satisfação no trabalho. In: SIQUEIRA, M. M. M. (Org.). Medidas do comportamento organizacional: ferramentas de diagnóstico e de gestão. Porto Alegre: Artmed, 2008. p. 265-275.

SIQUEIRA, M. M. M.; GOMIDE JÚNIOR, S. Vínculos do indivíduo com o trabalho e com a organização. In: ZANELLI, J. C.; BORGES-ANDRADE, J. E.; BASTOS, A. V. B. (Orgs.). Psicologia, organizações e trabalho no Brasil. Porto Alegre: Artmed, 2004. p. 300-328.

STAW, B. M.; ROSS, J. Stability in the midst of change: a dispositional approach to job attitudes. Journal of Applied Psychology, v. 70, p. 469-480, 1985.

STOREY, J. New perspectives in human resource management. London: Routledge, 1995.

SUBRAMONY, M. A meta-analytic investigation of the relationship between HRM bundles and firm performance. Human Resources Management, v. 48, n. 5, p. 745-768, 2009.

TABACHNICK, B.; FIDELL, L. S. Using multivariate statistics. 5. ed. Boston: Allyn and Bacon, 2007.

TENBRUNSEL, A. E.; GALVIN, T. L.; NEALE, M. A.; BAZERMAN, M. H. Cognições em organizações. In: CLEGG, S. R.; HARDY, C.; NORD, W. R. (Orgs.). Handbook de Estudos Organizacionais, São Paulo: Atlas, 2004. v. 3, p. 33-68.

TURNER, R.; HUEMANN, M.; KEEGAN, A. Human resource management in the project-oriented organization: employee well-being and ethical treatment. The International Journal of Project Management, v. 26 , n. 5 , p. 577-585, 2008.

ULRICH, D., HALBROOK, R., MEDER, D., STUCHLIK, M.; THORPE, S. Employee and customer attachment: synergies for competitive advantage. Human Resource Planning, v. 14, n. 2, p. 89-103, 1991.

WEISS, H. M. Desconstructing job satisfaction: separations, beliefs and affective experiences. Human Resource Management Review, v. 12, n. 2, p. 173-194, 2002.

WILKINSON, A.; BACON, N.; REDMAN, T.; SNELL, S. The sage handbook of human resource management. London: Sage Publications, 2010. 